Article

\title{
Experimental Implementation and Theoretical Investigation of a Vanadium Dioxide Optical Filter for Bit Error Rate Enhancement of Enhanced Space Shift Keying Visible Light Communication Systems
}

\author{
Dimitra K. Manousou, Argyris N. Stassinakis, Emmanuel Syskakis, Hector E. Nistazakis *, \\ Spiros Gardelis $(\mathbb{D}$ and George S. Tombras \\ Faculty of Physics, National and Kapodistrian University of Athens, 15784 Athens, Greece; \\ dimmanous@phys.uoa.gr (D.K.M.); a-stasinakis@phys.uoa.gr (A.N.S.); esysk@phys.uoa.gr (E.S.); \\ sgardelis@phys.uoa.gr (S.G.); gtombras@phys.uoa.gr (G.S.T.) \\ * Correspondence: enistaz@phys.uoa.gr; Tel.: +30-210-7276710
}

Received: 30 April 2019; Accepted: 11 June 2019; Published: 13 June 2019

\begin{abstract}
Visible Light Communication (VLC) systems use light-emitting diode (LED) technology to provide high-capacity optical links. The advantages they offer, such as the high data rate and the low installation and operational cost, have identified them as a significant solution for modern networks. However, such systems are vulnerable to various exogenous factors, with the background sunlight noise having the greatest impact. In order to reduce the negative influence of the background noise effect, optical filters can be used. In this work, for the first time, a low-cost optical vanadium dioxide $\left(\mathrm{VO}_{2}\right)$ optical filter has been designed and experimentally implemented based on the requirements of typical and realistic VLC systems in order to significantly increase their performance by reducing the transmittance of background noise. The functionality of the specific filter is investigated by means of its bit error rate (BER) performance estimation, taking into account its experimentally measured characteristics. Numerous results are provided in order to prove the significant performance enhancement of the VLC systems which, as it is shown, reaches almost six orders of magnitude in some cases, using the specific experimental optical filter.
\end{abstract}

Keywords: bit error rate; VLC; experimental optical filter; eSSK; $\mathrm{VO}_{2}$ filter

\section{Introduction}

The Visible Light Communication (VLC) systems that use light-emitting diode (LED) technology to transmit the information signal have attracted research and commercial interest during the last few years due to the advantages that they offer [1-8]. The use of the visible electromagnetic (EM) spectrum, between $400 \mathrm{~nm}$ and $700 \mathrm{~nm}$, and the high responsivity of LED lamps offer a high data rate performance suitable for modern networks with high capacity requirements [9]. Additionally, the visible EM spectrum is environmentally and biologically safe and no license is required to use it, while, due to the evolution of semiconductor technology, low-cost and low energy consumption LED lamps are used. All these advantages have identified VLC systems as a highly accessible solution for next-generation communication networks [10,11], as well as for smart home and smart city applications [12,13]. However, such systems can be affected by various factors that degrade their performance and most of them are difficult to predict or eliminate.

The main factor that significantly affects and decreases the performance of VLC systems is the background noise, which mainly originates from sunlight radiation, and this is the main reason why such communication systems are mostly used for indoor applications [14]. One of the most 
effective techniques that reduces the sunlight background noise is the appliance of suitable optical filters at the receiver in order to decrease the noise power in the wavelength range that is not used for data transmission [15]. In this work, a low-cost vanadium dioxide $\left(\mathrm{VO}_{2}\right)$ thin film is developed and experimentally investigated in order to be evaluated as an optical band-pass filter in front of the receiver of a VLC system to reject the wavelength range of the EM spectrum, which is not used for data transmission, reducing the background noise. The proposed optical filter consists of a thin densified film of $\mathrm{VO}_{2}$ deposited on a glass substrate. Its filtering capability utilizes the wavelength dependence of the optical transmittance of metallic phase $\mathrm{VO}_{2}$. In comparison to other (thin film) optical filters, such as interference (dichroic) filters [16], or other proposed filtering devices [17], it can be argued that $\mathrm{VO}_{2}$ can be as efficient but, in addition, being a single layer, it is easily fabricated by applying established experimental techniques, making it a more economical choice. Furthermore, the luminous transmittance of pure undoped $\mathrm{VO}_{2}$ might be favorably employed to a greater degree in the proposed filter as compared to, for example, the application of $\mathrm{VO}_{2}$ films as shielding layers in smart windows [18]. For this latter application, the presently achieved luminous transmittance of undoped $\mathrm{VO}_{2}$ thin films scarcely meets the requirements and a great research effort is devoted to the corresponding improvement on an international level. It should, however, be mentioned here that the transmittance performance of the proposed optical filter can further be improved, as will be discussed in Section 2 of the present work.

To investigate the performance of the proposed filter, four Red Green Blue (RGB) LED lamps are used in order to deploy a VLC communication system in an indoor environment in the presence of sunlight radiation. The room dimensions employed in the numerical calculations are not exactly the "typical ones", but a larger space has been chosen, in order to extract clearer conclusions about the effectiveness of the experimental optical filter under consideration, for the VLC links. The modulation scheme of space shift keying (SSK) which is used has proved to be a very effective technique for increasing the VLC system performance $[19,20]$. According to this technique, each LED lamp is active in a specific timeslot, transmitting a different symbol. In conventional SSK, every transmitter has an equal pulse duration and amplitude, but in order to further enhance this modulation technique, the pulse for each symbol has a unique time duration, creating the enhanced space shift keying (eSSK) modulation technique [21,22]. In order to investigate how the adjustment of an optical filter at the receiver enhances its performance, the bit error rate (BER) metric will be estimated for an indoor environment in the presence of sunlight radiation. To the best of our knowledge, it is the first time that such a low-cost, thin-film, $\mathrm{VO}_{2}$ optical filter has been proposed and experimentally evaluated as a component of a typical VLC system in order to reduce the background noise and improve the performance characteristics of the link. More specifically, as it will be shown in Section 6, taking into account the experimentally determined properties of the optical filter, the BER performance of a typical VLC link reaches a six orders of magnitude improvement.

The remainder of the work is organized as follows: In Section 2, the $\mathrm{VO}_{2}$ optical filter design and implementation will be analyzed; in Section 3, the characteristics of the system model will be presented; in Section 4, the signal-to-noise ratio (SNR) of the system will be estimated; in Section 5 , the BER performance will be estimated; and in Section 6, the corresponding numerical results will be presented.

\section{Vanadium Dioxide Filter Elaboration Procedure}

Bulk vanadium dioxide undergoes a fully reversible semiconductor to metal transition (SMT) when heated above $T_{S M T}=340 \mathrm{~K}$, which is accompanied by a structural transition. The dramatic changes of the electrical, optical, and thermal properties associated with the SMT transition have also been experimentally verified in thin $\mathrm{VO}_{2}$ films with thicknesses down to tens of $\mathrm{nm}[23,24]$. Above $T_{S M T}, \mathrm{VO}_{2}$ thin films are quite transparent at around $650 \mathrm{~nm}$, while they exhibit enhanced reflectance/absorption both in the UV and near-IR region. For wavelengths around $650 \mathrm{~nm}$, the absolute transparency of $\mathrm{VO}_{2}$ films can be enhanced by tailoring the chemical composition and microstructure 
of the material, as well as its geometrical features (thickness). This spectral variation of optical transparency appears very beneficial for an optical communication system employing a $\mathrm{VO}_{2}$ thin film as an optical filter in front of the receiver in order to reduce the background noise. The implementation of a $\mathrm{VO}_{2}$ optical filter might require the integration of a resistor in the form of a metal film as a heater in order to retain the film in its metallic phase and thus take advantage of its full filtering capability. Alternatively, the transition temperature $T_{S M T}$ might be tuned to the operation temperature of the device by the appropriate doping of $\mathrm{VO}_{2}$, as extensively researched in the literature [25-33].

Within the present investigation, high-quality $\mathrm{VO}_{2}$ films have been obtained by physical vapor deposition (PVD), which was employed to deposit $\mathrm{V}_{2} \mathrm{O}_{5}$ films on transparent, i.e., glass, substrates and conduct subsequent thermal reduction. Specifically, the $\mathrm{V}_{2} \mathrm{O}_{5}$ films, with an estimated thickness of $240 \mathrm{~nm}$, were reduced to monoclinic $\mathrm{VO}_{2}$ (M1) by annealing under steady nitrogen $\left(\mathrm{N}_{2}\right)$ gas flow with a pressure of $0.4 \mathrm{mbar}$, at an annealing temperature of about $500^{\circ} \mathrm{C}$ for $3 \mathrm{~h}$. The transformation of $\mathrm{V}_{2} \mathrm{O}_{5}$ to pure monoclinic $\mathrm{VO}_{2}$ (M1) phase was monitored by x-ray diffraction (XRD) analysis on a Siemens D 5000 diffractometer with $\mathrm{Cu} \mathrm{K} \alpha$ radiation at a $2 \theta$-step of $0.03^{\circ}$ and a counting time of $2 \mathrm{~s} / \mathrm{step}$.

To investigate the changes of the electrical and optical properties of $\mathrm{VO}_{2}$ films around the SMT, electrical resistance was measured in the temperature range of 300-380 K where the SMT takes place, using a 225 Keithley current source and a DMM 2000 Keithley voltmeter. For the same purpose, optical transmittance was measured on the same specimen, at a wavelength of $\lambda=1550 \mathrm{~nm}$ within the SMT temperature region, i.e., $300-350 \mathrm{~K}$. We used an LED diode emitting at $1550 \mathrm{~nm}$ as a source, while the detection was performed by an InGaAs photodiode. In addition, optical transmittance was measured within the spectral region $400-1000 \mathrm{~nm}$ at room temperature and $T>T_{S M T}$. A Xe lamp monochromated through an Oriel monochromator was used as a light source for the transmittance and a calibrated silicon photodiode was used for the detection of the transmitted light. In our calculations, we took into account the contribution of the bare substrate. For the transmittance experiments, we designed a special heating stage to achieve isothermal conditions over the film area and their temperature was monitored by a NiCr-Constantan thermocouple in contact with the films.

According to the results shown in Figure 1a, the low-current DC-electrical resistance of a $\mathrm{VO}_{2}$ thin film on a glass substrate exhibits a sharp SMT at $T_{S M T}=340 \mathrm{~K}$, resulting in a drop of approximately three orders of magnitude. The same film exhibited an abrupt decrease of $40 \%$ of the optical transmittance in the near infrared region, i.e., $\lambda=1550 \mathrm{~nm}$, at $T_{S M T}$, as shown in Figure $1 \mathrm{~b}$. The narrow $(\sim 5 \mathrm{~K})$ thermal hysteresis loops depicted in Figure 1 for both measurements can be attributed to the first-order structural (monoclinic to tetragonal (rutile)) transition accompanying the SMT transition.
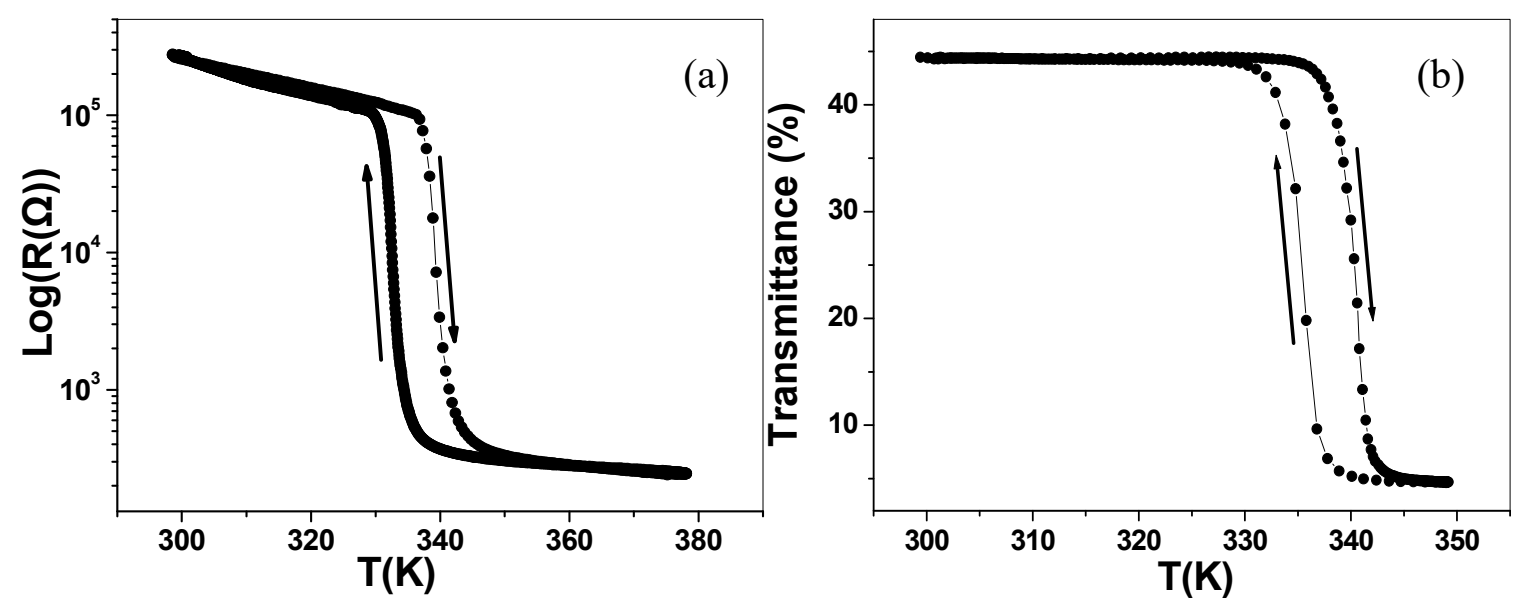

Figure 1. (a) Temperature dependence of the electrical resistance of a $\mathrm{VO}_{2}$ thin film on glass at $\mathrm{T}=300-380 \mathrm{~K}$, as has been experimentally measured; $(\mathbf{b})$ temperature dependence of the optical transmittance of a $\mathrm{VO}_{2}$ thin film on glass at $\lambda=1550 \mathrm{~nm}$ for $\mathrm{T}=300-350 \mathrm{~K}$, as has been experimentally measured. 
The results of a typical measurement of the optical transmittance within the spectral range $400 \mathrm{~nm} \leq \lambda \leq 1000 \mathrm{~nm}$ at $\mathrm{T} \approx 300 \mathrm{~K}$ and at $\mathrm{T}=370 \mathrm{~K}$ are shown in Figure 2. As presented in Figure 2, the rutile (metallic) $\mathrm{VO}_{2}$ film $(\mathrm{T}=370 \mathrm{~K}$ ) exhibits remarkably low transmittance between $350 \mathrm{~nm} \leq$ $\lambda \leq 500 \mathrm{~nm}$, combined with a progressive decrease of the transmittance in the near infrared region upon an increasing wavelength. In the monoclinic insulating phase, i.e., at $\mathrm{T}=300 \mathrm{~K}<T_{S M T}$, the transmittance increases steadily for any wavelength, while it is almost identical to that of the rutile phase in the UV region, see Figure 2. Accordingly, the overall spectral variation of the transmittance attains a "hanging bell" shape in the visible light region, with a broad peak centered at $650 \mathrm{~nm}$-where an overall transmittance of $25 \%$ is obtained-suggesting a unique radiation-shielding ability of $\mathrm{VO}_{2}$ thin films extending on both sides of the visible light region. Therefore, rutile $\mathrm{VO}_{2}$ films appear highly promising as absorption/reflectance materials for solar radiation shielding performance.

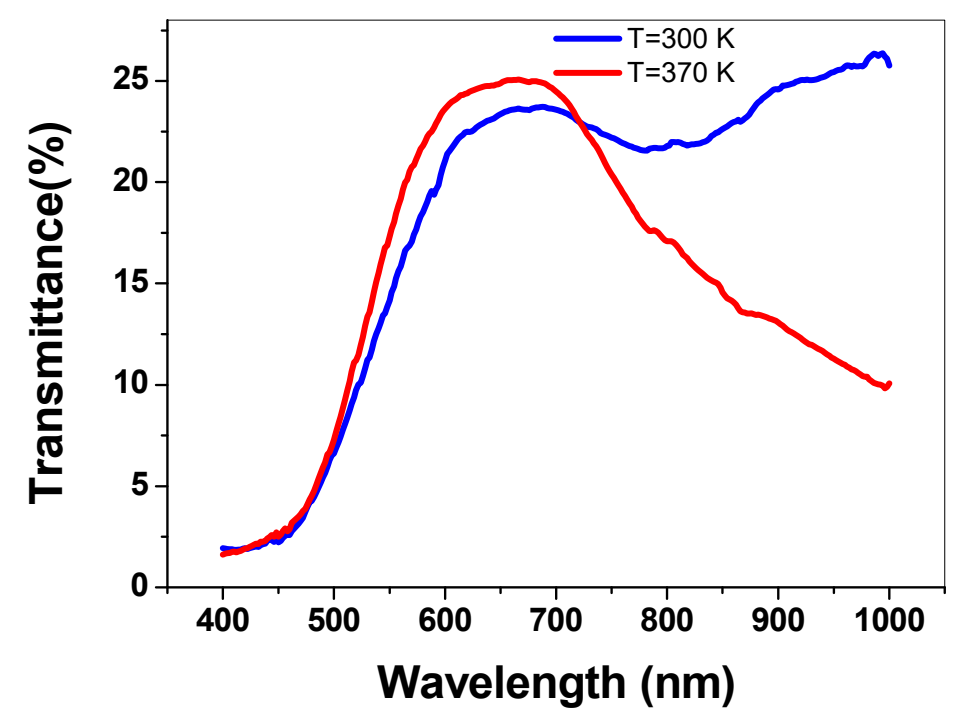

Figure 2. Optical transmittance of a $\mathrm{VO}_{2}$ thin film on glass below $(300 \mathrm{~K})$ and above $(370 \mathrm{~K}) \mathrm{T}_{S M T}$ upon wavelength variation in the range $400-1000 \mathrm{~nm}$.

The experimental results shown in Figures 1 and 2 are in good agreement with recent experimental [34-38], as well as theoretical, literature reports [39]. The sharp decrease of both the electrical resistance and T-dependent IR-transmittance observed around the SMT transition indicates the high-phase purity and adequate crystallinity of the $\mathrm{VO}_{2}$ films, in accordance with the obtained XRD patterns. The spectral variation of the transmittance of rutile $\mathrm{VO}_{2}$ shown in Figure 2 at $\lambda \geq 750 \mathrm{~nm}$ reflects a synergetic combination of simultaneously increasing reflectivity and absorption [40] and is thus governed by the intrinsic properties of the material. The strong absorption in the IR region is likely due [41] to the plasma oscillation of the conduction electrons in the metallic phase, indicating a direct correlation with the electrical conductivity of the material in the metallic phase. This, in turn, can be reasonably closely related to the tunability of the filter, as an increase of the electrical conductivity of metallic $\mathrm{VO}_{2}$ can be expected to result in a higher rejection (i.e., lower transmittance) of near IR radiation. On the other hand, it should be remarked that the steep increase of the optical transmittance at $450 \mathrm{~nm} \leq \lambda \leq 600 \mathrm{~nm}$ shown in Figure 2 is insensitive to the electrical conduction, as well as changes of the crystal symmetry and the structural transition (monoclinic to rutile) of the material. This effect should thus be related to fundamental band-structural features of $\mathrm{VO}_{2}$, like the band gap between valence bands formed by $\mathrm{O} 2 \mathrm{p}$ states and the $\pi^{*}$ band, in accordance with previous work [28]. Within this scenario, narrowing the band pass width of the proposed filter might be attempted by band gap engineering of the material. A decrease of the band gap width would be desirable for this specific application, which could involve the doping of $\mathrm{VO}_{2}$ with properly selected cations. However, it should be emphasized that no such effort has been reported yet, to the best of our knowledge. 
According to recent experimental data, the spectral variation of the transmittance of a $50 \mathrm{~nm}$ and $100 \mathrm{~nm}$ rutile $\mathrm{VO}_{2}$ film coating-dispersed nanoparticles, as well as of a $50 \mathrm{~nm} \mathrm{VO}_{2}$ compacted film, forms a "hanging bell" shape in the visible light region [40,42]. The largest transmittance values are found at $670 \mathrm{~nm}$, with an overall transmittance of $53 \%, 29.5 \%$, and $36.2 \%$ respectively, showing that the maximum transmittance increases as the thickness of the films decreases. Alternatively, the luminous transmittance of rutile $\mathrm{VO}_{2}$ films might also be enhanced by adequate doping. For example, Fe-doped $\mathrm{VO}_{2}$ thin films prepared on glass substrates by direct current (DC) magnetron sputtering with a thickness of about $150 \mathrm{~nm}$, show an increase of optical transmittance at $670 \mathrm{~nm}$ with the increase of Fe-content, maintaining an almost symmetric "hanging bell" shape at around this wavelength [33].

\section{System Model}

We assume that four white RGB LED lamps are installed on the ceiling of a typical rectangular room for illumination and data transmission using the red color, i.e., a wavelength range between $600 \mathrm{~nm}$ and $700 \mathrm{~nm}$. A simple pattern for the placement of LED lamps that is mostly used in indoor environments will be used and is presented in Figure 3.

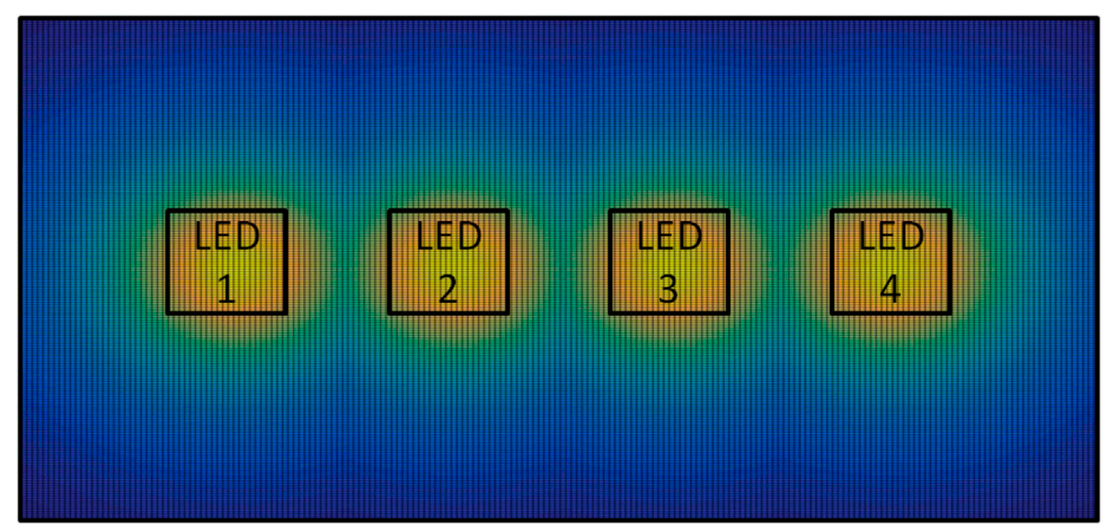

Figure 3. Ceiling overview of the light-emitting diode (LED) pattern.

The emission pattern of each LED lamp of Figure 3 follows the Lambertian model, which accurately describes the spatial power diffusion of an LED lamp [43-46]. Therefore, assuming that the optical power transmitted is $P_{t}$, the power at the receiver, $P_{r}$, will be given as $[43,44]$

$$
P_{r}=P_{t} A \frac{m+1}{2 \pi d^{2}} \cos ^{m}(\varphi) \mathrm{T}_{s}(\psi) \cos (\psi), 0 \leq \psi \leq \Psi_{\mathcal{c}}
$$

where $m=-\ln (2) / \ln (\cos (\varphi))$ is the order of emission, $\varphi$ is the semi-angle at half power, $A$ is the physical area of the receiver's photodiode, $d$ is the distance between the transmitter and the receiver, $\psi$ is the angle of normalized irradiance, $T_{S}(\psi)$ is the gain of the optical filter, and $\Psi_{\mathcal{C}}$ stands for the width of the field of view (FOV) at the receiver.

\section{SNR Estimation}

The signal-to-noise ratio (SNR) represents a very significant parameter for the communication systems. This parameter is the ratio of the signal's power to the power of the noise and can be calculated as $[40,44]$

$$
S N R=\frac{P_{r}}{\sigma_{\text {tot }}^{2}}
$$

where $\sigma^{2}$ tot is the total noise variance and is given as $[40,44]$

$$
\sigma_{\text {tot }}^{2}=\sigma_{\text {thermal }}^{2}+\sigma_{\text {shot }}^{2}
$$


with $\sigma_{\text {thermal }}$ being the variance of thermal noise that is generated by the thermal agitation of charge carriers inside a conductor and $\sigma_{\text {shot }}$ is the shot noise due to ambient light. These variances can be estimated through the following mathematical expressions [43,47]:

$$
\sigma_{\text {thermal }}^{2}=\frac{8 \pi k T_{k} n A I_{2} B^{2}}{G}+\frac{16 \pi^{2} k T_{k} \Gamma n^{2} A^{2} I_{3} B^{3}}{g_{m}}
$$

and

$$
\sigma_{\text {shot }}^{2}=2 q \gamma P_{r} B+2 q \gamma P_{b g} I_{2} B
$$

where $k$ stands for the Boltzmann's constant, $G$ is the open loop voltage gain, $A$ is the physical area of the receiver, $T_{k}$ is the absolute temperature, $I_{2}$ and $I_{3}$ are noise bandwidth factors, $n$ is the capacitance of the photo detector per unit area, $g_{m}$ is the transconductance, $B$ is the noise bandwidth, $q$ is the electronic charge, and $P_{b g}$ is the background noise power.

Assuming that the background noise of the system depends on sunlight radiation, $P_{b g}$, can be estimated as [14]

$$
P_{b g}=E_{\text {det }} T_{0} A n_{r i}{ }^{2}
$$

where $T_{0}$ is the peak filter transmission coefficient, $n_{r i}$ is the refractive index of the lens, and $E_{\text {det }}$ is the irradiance within the spectral range of the receiver. Additionally, $E_{\text {det }}$ is the irradiance of the receiver between the wavelengths $\lambda_{1}, \lambda_{2}$ and can be estimated as [14]

$$
E_{\text {det }}=\int_{\lambda_{1}}^{\lambda_{2}} \frac{S_{\text {peak }} W(\lambda)}{\max [W(\lambda)]} d \lambda
$$

where $S_{\text {peak }}$ is the peak irradiance and $W(\lambda)$ is the spectral irradiance of a black body radiation model and is given as [14]

$$
W(\lambda)=\frac{1}{\lambda^{5}}\left(\frac{2 \pi h_{p} c^{2}}{e^{\frac{h_{p c}}{\lambda k T_{B}}}-1}\right)
$$

where $h_{p}$ is the Planck's constant, $c$ is the speed of light in a vacuum, and $T_{B}$ is the average surface temperature of the Sun in Kelvin degrees. The integral of Equation (7) cannot be solved analytically, so the accurate numerical method of Monte Carlo is used in order to estimate the solar background irradiance at the receiver, using $10^{6}$ random samples. In order to improve the SNR of the system, the $\mathrm{VO}_{2}$ filter implemented can be installed at the receiver in order to reduce the sunlight radiation received. According to Figure 2, the filter is able to reduce the transmittance of the sunlight background noise power, especially for wavelengths lower that $600 \mathrm{~nm}$. Furthermore, the transmittance presents its peak value at $650 \mathrm{~nm}$, representing the wavelength at which the information is transmitted, so power reduction of the signal will be less than the reduction of the noise. This characteristic is very important for the selection of a suitable optical filter.

\section{BER Estimation for eSSK}

In order to examine how the use of the optical filter affects the performance of the VLC system, its BER performance is investigated. The modulation technique of SSK will be implemented in this VLC system. This technique is a kind of spatial modulation where every LED lamp will transmit a different symbol when it is on. For $N_{b}$ bit per symbol, the number of symbols $N_{s}$ that can be created is [48]

$$
N_{s}=2^{N_{b}}
$$

Therefore, for 2 bit per symbol, four transmitters are required, one for each symbol. In order to reduce the probability of error, different pulse durations for each symbol can be used by deploying the 
technique of eSSK. More specifically, the time duration of each symbol will be $\tau_{i} T$, with $T$ being the duration of symbol of the SSK technique and $\tau_{i}$ being the factor that corresponds to the specific pulse width in eSSK.

The BER for the eSSK scheme is given as [21,22]

$$
B E R \leq \frac{4}{N(\mathrm{~N}-1) \log _{2}(\mathrm{M})} \sum_{j=1}^{N-1} \sum_{i=j+1}^{N} Q\left(\sqrt{\frac{T N}{4 S} S N R\left(\left\|\tau_{i} h_{i 1}-\tau_{j} h_{j 1}\right\|_{F}\right)^{2}}\right)
$$

with $N$ being the number of transmitters; $M$ representing the number of symbols of the system; $S=\sum_{i=1}^{N} \tau_{i},\|.\|_{\mathrm{F}}$ standing for the Frobenius norm for matrices; and $h_{i k}$ being the channel gain between the $i$-th transmitter and the $k$-th receiver, where, for our system, $k=1$, consisting of the channel's gain matrix $H(t)=\left[\begin{array}{lllll}h_{11} & h_{12} & h_{13} & \ldots & h_{1 N}\end{array}\right]^{T}$ [21,22]. The channel gain matrix, $H(\mathrm{t})$, for every transmitter can be calculated as the ratio of the total received optical power on the receiver to the transmitted optical power [49]:

$$
h_{i 1}=\frac{P_{r_{i}}}{P_{t_{i}}}
$$

\section{Numerical Results}

In this section, the numerical outcomes for the BER of an eSSK VLC system are presented. The LED transmitters are installed on the ceiling of a typical room with the dimensions $10 \mathrm{~m} \times 6 \mathrm{~m} \times 3 \mathrm{~m}$ in the following coordinates: LED1(2,3), LED2(4,3), LED3(6,3), and LED4(8,3). The length and width of the room were chosen to be greater than the standard model, i.e., $5 \mathrm{~m} \times 5 \mathrm{~m} \times 5 \mathrm{~m}$, in order to cover more space and have an extensive view of the results. However, using the above mentioned expressions, the system's performance can be accurately estimated for any choice of room dimensions. The receiver is placed at the plane of $1.5 \mathrm{~m}$ above the floor. The technical characteristics of the LED transmitters and the receiver, which constitute typical values for realistic VLC systems, are presented in Table 1.

Table 1. Values of noise and system parameters.

\begin{tabular}{ll}
\hline Parameter & Value \\
\hline Transmitted Optical Power- $\mathrm{P}_{\mathrm{t}}$ & $20 \mathrm{~W}$ \\
\hline Semi-angle at half power- $\Phi_{\mathrm{s}}$ & $35^{\circ}$ \\
\hline Receivers FOV & $70^{\circ}$ \\
\hline Physical Area of the receiver-A & $1 \mathrm{~cm}^{2}$ \\
\hline Refractive index of the lens- $\mathrm{n}_{\mathrm{ri}}$ & 1.5 \\
\hline Absolute temperature of the room- $\mathrm{T}_{\mathrm{k}}$ & $297 \mathrm{~K}$ \\
\hline Photodetector's capacitance- $\mathrm{n}$ & $1.12 \mu \mathrm{m}^{-2}$ \\
\hline Noise bandwidth factor $\mathrm{I}_{2}$ & 0.562 \\
\hline Noise bandwidth factor $\mathrm{I}_{3}$ & 0.0868 \\
\hline Noise Bandwidth-B & $175 \mathrm{MHz}$ \\
\hline Open loop voltage Gain- $\mathrm{G}$ & 10 \\
\hline Channel noise factor- $\Gamma$ & 1.5 \\
\hline Transconductance- $\mathrm{g}_{\mathrm{m}}$ & $30 \mathrm{~ms}$ \\
\hline
\end{tabular}

In Figure 4, the BER performance of the specific VLC system, without the use of the $\mathrm{VO}_{2}$ optical filter, is presented. The maximum and minimum values of the BER are 0.38 and $8.1 \times 10^{-9}$, respectively. 
It is clear that the performance of the VLC system degrades at the edges of the room, where the received power is lower and as a result, the SNR of the system decreases significantly compared with the values which are obtained in the center. Additionally, it can also be observed that the BER increases in the areas between the LED lamps, where the values of channel gain are almost the same for two LED transmitters and thus, the receiver cannot easily recognize the source of the signal.

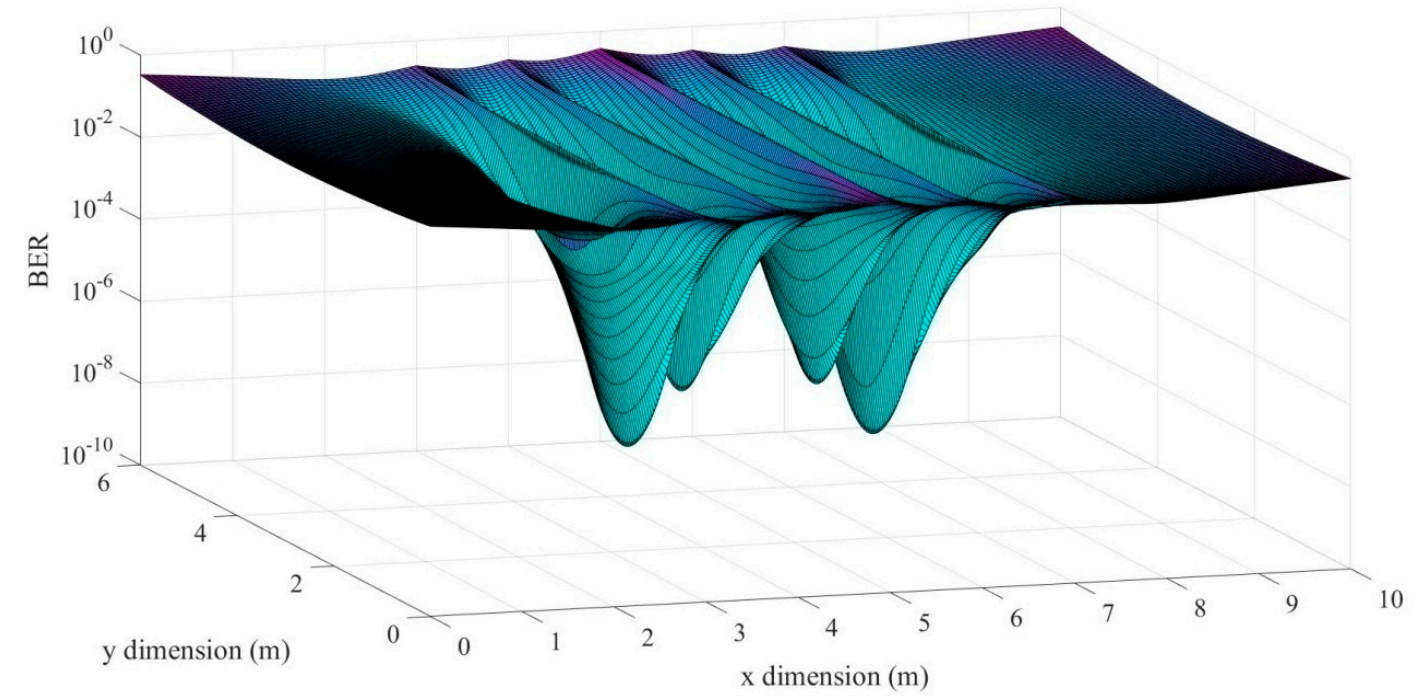

Figure 4. Bit error rate (BER) of the visible light communication (VLC) system under consideration, without the $\mathrm{VO}_{2}$ optical filter.

In Figure 5, the BER results are presented in the case where the $\mathrm{VO}_{2}$ optical filter is used at the receiver of the VLC system. It can be easily seen that the use of the filter can greatly increase the performance of the VLC system as the BER values lie between a minimum value of $1.5 \times 10^{-15}$ and a maximum of 0.33 . Therefore, the BER performance improvement which has been achieved is significant as it is almost six orders of magnitude better, in the best case.

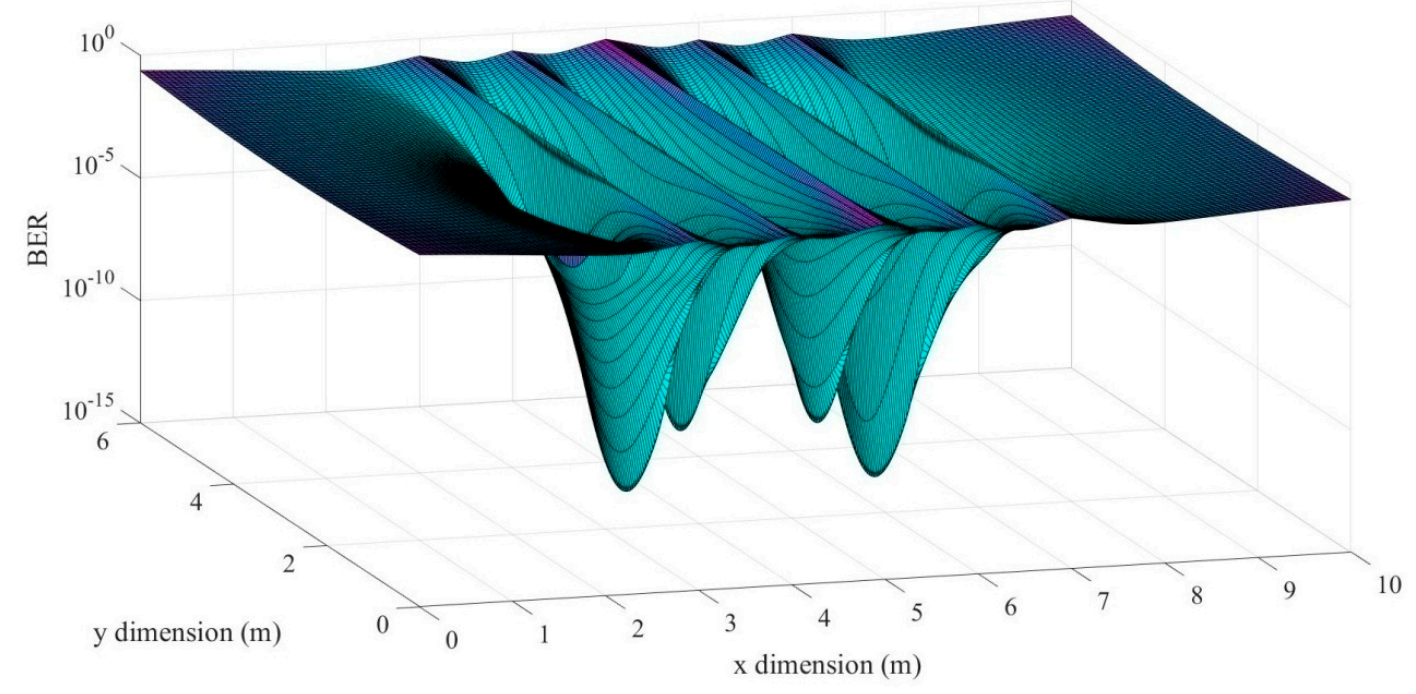

Figure 5. Bit error rate (BER) of the visible light communication (VLC) system under consideration, using the $\mathrm{VO}_{2}$ optical filter at the receiver.

Figure 6 shows the BER performance of the VLC system when no filter is applied. Figure 7 shows the effect of using the $\mathrm{VO}_{2}$ filter. More specifically, in the colored area on the left of the panels, in both 
figures, the BER performance of the system is lower than $1 \times 10^{-6}$, which is an average value of BER for the specific VLC system. It can be seen that the application of the optical filter significantly increases the area with a lower BER, making the VLC system much more reliable.
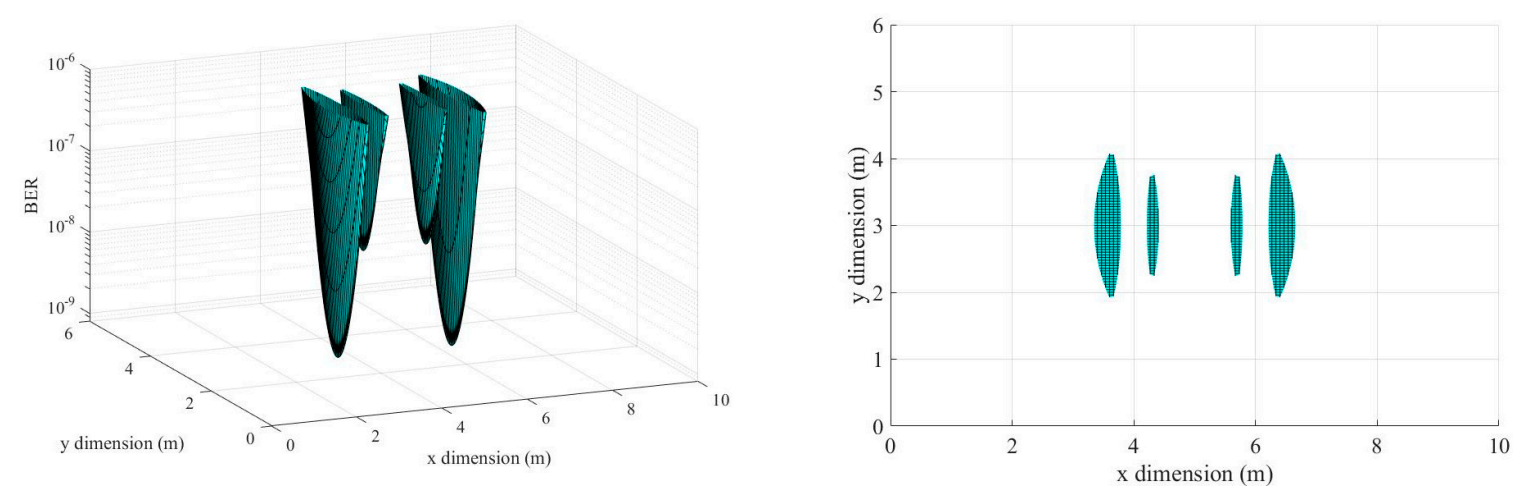

Figure 6. Areas with a bit error rate $(\mathrm{BER}) \leq 1 \times 10^{-6}$ for the case where no filter is applied in the visible light communication (VLC) system.
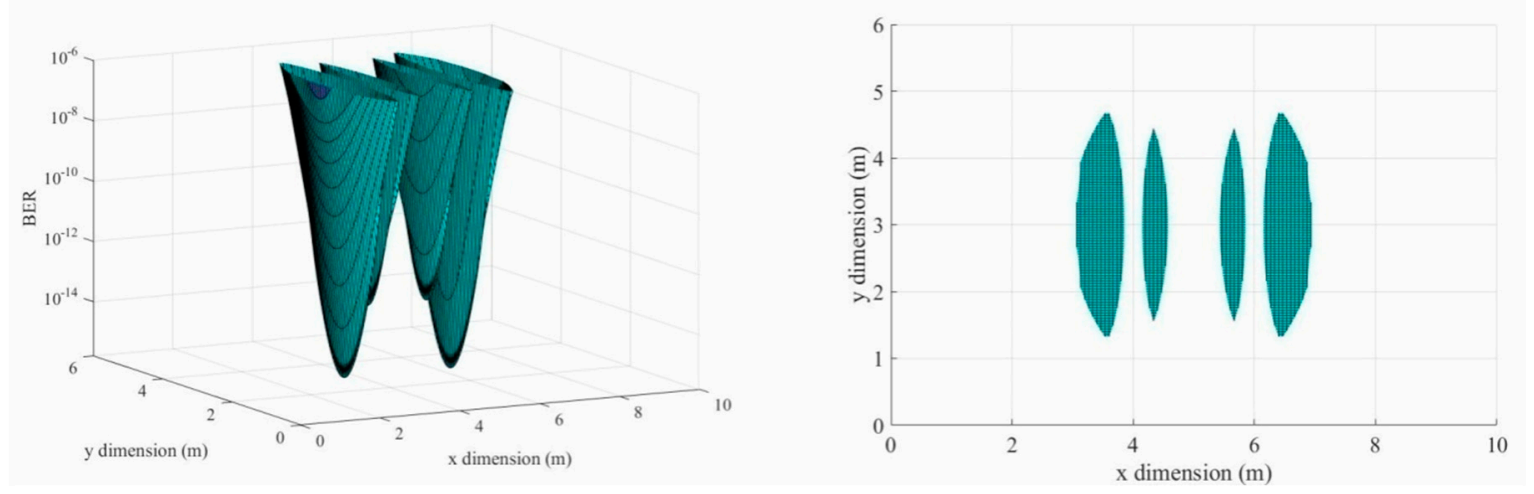

Figure 7. Areas with a bit error rate $(B E R) \leq 1 \times 10^{-6}$ for case where the $\mathrm{VO}_{2}$ filter is applied at the receiver of the visible light communication (VLC) system.

Summarizing the above results, it is demonstrated that the BER performance of the specific VLC system using $\mathrm{VO}_{2}$ as an optical filter in front of the receiver has been remarkably improved. Specifically, according to the numerical results, the maximum and minimum values of the BER are decreased from 0.38 to 0.33 and $8.1 \times 10^{-9}$ to $1.5 \times 10^{-15}$, respectively. In addition, Figures 6 and 7 show that the effect of using the proposed filter increases the area with a lower BER. Therefore, it is clearly evidenced that the use of $\mathrm{a} \mathrm{VO}_{2}$ thin film as an optical filter in VLC links results in a significant enhancement of their performance. Even higher improvement could be achieved if the transmittance bandwidth of $\mathrm{VO}_{2}$ thin films was narrowed by displacing the shorter cut-off wavelength to values closer to $600 \mathrm{~nm}$ in order to favorably exclude sunlight noise peaking at $500 \mathrm{~nm}$. This might be accomplished with adequate doping, resulting in bandgap narrowing of $\mathrm{VO}_{2}$ thin films. Apart from this potentiality, the decrease of the thickness of the film, as has been already mentioned, provides a straightforward possibility to boost the optical transmittance at $600-700 \mathrm{~nm}$. Therefore, our present results and the mentioned optimization possibilities provide convincing evidence for the use of $\mathrm{VO}_{2}$ thin films as a greatly efficient optical filter in VLC links.

\section{Conclusions}

In this work, the experimental design and implementation of a vanadium dioxide thin film as an optical band-pass filter, in order to be used in a typical VLC link, is presented. Exploiting its properties, the performance of a realistic VLC system using the specific optical filter for reducing the sunlight 
background noise is investigated. The optical system is assumed to use the eSSK technique and its BER performance is estimated. From the presented results, it is demonstrated that the use of the optical filter can significantly alter the capabilities of the system, by increasing the BER performance by up to six orders of magnitude in many cases and thus appears suitable for high-performance networks. Moreover, the radiation shielding performance of $\mathrm{VO}_{2}$ optical filters can be further improved, either by increasing the transmittance for the wavelength employed as the signal carrier or/and by making the transmittance curve much narrower. A further investigation is currently under way to improve the performance of the $\mathrm{VO}_{2}$ filter by reducing the film thickness and using dopants in order to engineer the energy band gap of $\mathrm{VO}_{2}$ and thus its transmittance spectrum.

Author Contributions: Conceptualization, D.K.M., A.N.S., E.S., H.E.N., and S.G.; methodology, D.K.M., A.N.S., E.S., H.E.N., and S.G.; software, D.K.M. and A.N.S.; validation, D.K.M., A.N.S., E.S., H.E.N., and S.G.; investigation, D.K.M., A.N.S., E.S., H.E.N., S.G., and G.S.T.; resources, D.K.M., A.N.S., E.S., H.E.N., S.G., and G.S.T.; writing—original draft preparation, D.K.M., A.N.S., E.S., H.E.N., and S.G.; writing-review and editing, D.K.M., A.N.S., E.S., H.E.N., S.G., and G.S.T.; supervision, E.S., H.E.N., S.G., and G.S.T.; funding acquisition, H.E.N. and G.S.T.

Funding: This research was funded by European Union's Horizon 2020 research and innovation program, grant number 777596 .

Conflicts of Interest: The authors declare no conflict of interest.

\section{References}

1. Sivabalan, A.; John, J. Modeling and Simulation of Indoor Optical Wireless Channels: A Review. In Proceedings of the TENCON 2003, Conference on Convergent Technologies for Asia-Pacific Region, Bangalore, India, 15-17 October 2003; Volume 3, pp. 1082-1085. [CrossRef]

2. Karunatilaka, D.; Zafar, F.; Kalavally, V.; Pathiban, R. LED Based Indoor Visible Light Communications: State of the Art. IEEE Commun. Surv. Tutor. 2015, 17, 1649-1678. [CrossRef]

3. Medina, C.; Zambrano, M.; Navarro, K. Led Based Visible Light Communication: Technology, Applications and Challenges-A Survey. Int. J. Adv. Eng. Technol. 2015, 8, 482-495. [CrossRef]

4. Lee, K.; Park, H.; Barry, J.R. Indoor Channel Characteristics for Visible Light Communications. IEEE Commun. Lett. 2011, 15, 217-219. [CrossRef]

5. Fahamuel, P.; Thompson, J.; Haas, H. Performance analysis of indoor diffuse VLC MIMO channels using Angular Diversity Detectors. J. Lightwave Technol. 2016, 34, 1254-1266. [CrossRef]

6. Ogunkoya, F.B.; Popoola, W.O.; Sinanović, S. Pilot-assisted PAPR reduction technique for O-OFDM using multiple LEDs in VLC systems. In Proceedings of the 2016 IEEE International Conference on Communications Workshops (ICC), Kuala Lumpur, Malaysia, 23-27 May 2016; pp. 309-314. [CrossRef]

7. Nistazakis, H.E.; Stassinakis, A.N.; Muhammad, S.S.; Tombras, G.S. BER Estimation for Multi Hop RoFSO QAM or PSK OFDM Communication Systems Over Gamma Gamma or Exponentially Modeled Turbulence Channels. Elsevier Opt. Laser Technol. 2014, 64, 106-112. [CrossRef]

8. Peppas, K.P.; Stassinakis, A.N.; Topalis, G.K.; Nistazakis, H.E.; Tombras, G.S. Average capacity of optical wireless communication systems over I-K atmospheric turbulence channels. IEEE/OSA J. Opt. Commun. Netw. 2012, 4, 1026-1032. [CrossRef]

9. Linnartz, J.P.M.G.; Feri, L.; Yang, H.; Colak, S.B.; Schenk, T.C.W. Communications and Sensing of Illumination Contributions in a Power LED Lighting System. In Proceedings of the 2008 IEEE International Conference on Communications, Beijing, China, 19-23 May 2008; pp. 5396-5400. [CrossRef]

10. Feng, L.; Hu, R.Q.; Wang, J.; Xu, P.; Qian, Y. Applying VLC in 5G Networks: Architectures and Key Technologies. IEEE Netw. 2016, 30, 77-83. [CrossRef]

11. Wu, S.; Wang, H.; Youn, C. Visible light communications for $5 \mathrm{G}$ wireless networking systems: From fixed to mobile communications. IEEE Netw. 2014, 28, 41-45. [CrossRef]

12. Leitgeb, E.; Plank, T.; Pezzei, P.; Ivanov, H.; Pérez-Jiménez, R. Optical Wireless Communications and Optical Sensing and Detection Technologies for Increasing the Reliability and Safety in Autonomous Driving Scenarios. In Proceedings of the 2018 20th International Conference on Transparent Optical Networks (ICTON), Bucharest, Romania, 1-5 July 2018; pp. 1-4. [CrossRef] 
13. Bekhrad, P.; Ivanov, H.; Leitgeb, E. Car to X Communication with Optical Wireless as Support and Alternative to RF-Technologies for Roads and Future Transportation. In Proceedings of the 2018 26th International Conference on Software, Telecommunications and Computer Networks (SoftCOM), Split, Croatia, 13-15 September 2018; pp. 1-6. [CrossRef]

14. Kim, H.C.; Kim, B.W.; Jung, S.Y. Performance of a wavelength hopping MC-VPPM scheme for vehicle-to-infrastructure (V2I) VLC. Photonic Netw. Commun. 2017, 33, 60-68. [CrossRef]

15. Manousou, D.K.; Stassinakis, A.N.; Syskakis, E.; Nistazakis, H.E.; Tombras, G.S.; Volos, C.K.; Tsigopoulos, A.D. Estimation of the influence of Vanadium Dioxide Optical Filters for the Performance of Visible Light Communication Systems. In Proceedings of the 2018 7th International Conference on Modern Circuits and Systems Technologies (MOCAST), Thessaloniki, Greece, 7-9 May 2018; pp. 1-4. [CrossRef]

16. Ge, P.; Liang, X.; Wang, J.; Zhao, C. Optical Filters Design for Multi-Color Visible Light Communications. In Proceedings of the GLOBECOM 2017-2017 IEEE Global Communications Conference, Singapore, 4-8 December 2017; pp. 1-7. [CrossRef]

17. Chung, Y.H.; Oh, S. Efficient optical filtering for outdoor visible light communications in the presence of sunlight or articifical light. In Proceedings of the 2013 International Symposium on Intelligent Signal Processing and Communication Systems, Naha, Japan, 12-15 November 2013; pp. 749-752. [CrossRef]

18. Cao, X.; Jin, P. Solar Modulation Utilizing $\mathrm{VO}_{2}$-Based Thermochromic Coatings for Energy-Saving Applications. In Emerging Solar Energy Materials; IntechOpen: London, UK, 2018; Chapter 1. [CrossRef]

19. Videv, S.; Haas, H. Practical space shift keying VLC system. In Proceedings of the 2014 IEEE Wireless Communications and Networking Conference (WCNC), Istanbul, Turkey, 6-9 April 2014; pp. 405-409. [CrossRef]

20. Zhang, Q.; Bai, Z.; Zhang, N.; Sun, S.; Kwak, K.S. Performance Analysis of DC-SSK Scheme and Its Power Allocation in VLC System. In Proceedings of the 2018 International Conference on Computing, Networking and Communications (ICNC), Maui, HI, USA, 5-8 March 2018; pp. 280-284. [CrossRef]

21. Popoola, W.; Sinanovic, S.; Nistazakis, H.E. Enhancing the Error Performance of Optical SSK under Correlated Channel Condition. In Proceedings of the 2016 IEEE International Conference on Communications Workshops (ICC), Kuala Lumpur, Malaysia, 23-27 May 2016; pp. 7-11. [CrossRef]

22. Manganaris, K.N.; Nistazakis, H.E.; Stassinakis, A.N.; Tzanakaki, A.; Mkrttchian, G.; Tombras, G.S. Eight transmitter-short range indoor VLC system using spatial modulation technique of enhanced SSK with variable pulse width and correlated channel conditions. In Proceedings of the 7th International Conference on Experiments/Process/System Modeling/Simulation \& Optimization, 7th IC-EPSMSO, Athens, Greece, 5-8 July 2017; pp. 141-148.

23. Fan, L.L.; Chen, S.; Luo, Z.L.; Liu, Q.H.; Wu, Y.F.; Song, L.; Ji, D.X.; Wang, P.; Chu, W.S.; Gao, C.; et al. Strain Dynamics of Ultrathin VO2 Film Grown on TiO2 (001) and the Associated Phase Transition Modulation. Nano Lett. 2014, 14, 4036-4043. [CrossRef]

24. Paik, H.; Moyer, J.A.; Spila, T.; Tashman, J.W.; Mundy, J.A.; Freeman, E.; Shukla, N.; Lapano, J.M.; Engel-Herbert, R.; Zander, W.; et al. Transport properties of ultra-thin $\mathrm{VO}_{2}$ films on (001) $\mathrm{TiO}_{2}$ grown by reactive molecular-beam epitaxy. Appl. Phys. Lett. 2015, 107, 163101. [CrossRef]

25. Brown, B.L.; Lee, M.; Clem, P.G.; Nordquist, C.D.; Jordan, T.S.; Wolfley, S.L.; Leonhardt, D.; Edney, C.; Custer, J.A. Electrical and optical characterization of the metal-insulator transition temperature in Cr-doped $\mathrm{VO}_{2}$ thin films. J. Appl. Phys. 2013, 113, 173704. [CrossRef]

26. Krammer, A.; Arnaud, M.; Vitale, W.A.; Mocny, P.; Jeanneret, P.; Guibert, E.; Whitlow, H.J.; Ionescu, A.M.; Schüler, A. Elevated transition temperature in Ge doped $\mathrm{VO}_{2}$ thin films. J. Appl. Phys. 2017, 122, 4045304. [CrossRef]

27. Piccirillo, C.; Binions, R.; Parkin, I.P. Nb-Doped $\mathrm{VO}_{2}$ Thin Films Prepared by Aerosol-Assisted Chemical Vapour Deposition. Eur. J. Inorg. Chem. 2007, 2007, 4050-4055. [CrossRef]

28. Dietrich, M.K.; Kyhl, F.; Polity, A.; Klar, P.J. Optimizing thermochromic $\mathrm{VO}_{2}$ by co-doping with $\mathrm{W}$ and $\mathrm{Sr}$ for smart window applications. Appl. Phys. Lett. 2017, 110, 141907. [CrossRef]

29. Hanlon, T.J.; Coath, J.A.; Richardson, M.A. Molybdenum-doped vanadium dioxide coatings on glass produced by the aqueous sol-gel method. Thin Solid Films 2003, 436, 269-272. [CrossRef]

30. Dietrich, M.K.; Kramn, B.G.; Becker, M.; Meyer, B.K.; Polity, A.; Klar, P.J. Influence of doping with alkanine earth metals on the optical properties of thermochromic $\mathrm{VO}_{2}$. J. Appl. Phys. 2015, 117, 185301. [CrossRef] 
31. Mlyuka, N.R.; Niklasson, G.A.; Granqvist, C.G. Mg doping of thermochromic $\mathrm{VO}_{2}$ films enhances the optical transmittance and the decrease the metal-insulator transition temperature. Appl. Phys. Lett. 2009, 95, 171909. [CrossRef]

32. Liang, Z.; Zhao, L.; Meng, W.; Zhong, C.; Wei, S.; Dong, B.; Xu, Z.; Wan, L.; Wang, S. Tungsten-doped vanadium dioxide thin films as smart windows with self-cleaning and energy-saving functions. J. Alloys Compd. 2017, 694, 124-131. [CrossRef]

33. Lulu, L.; Zhiming, W.; Chunhui, J.; Meizhen, S.; Haoqian, F.; Xueting, M.; Yadong, J. Effect of Fe doping on thermochromic properties of $\mathrm{VO}_{2}$ films. J. Mater. Sci. Mater. Electron. 2018, 29, 5501-5508. [CrossRef]

34. Melnik, V.; Khatsevych, I.; Kladko, V.; Kuchuk, A.; Nikirin, V.; Romanyuk, B. Low-temperature method for thermochromic high ordered $\mathrm{VO}_{2}$ phase formation. Mater. Lett. 2012, 68, 215-217. [CrossRef]

35. Lee, S.; Meyer, T.L.; Park, S.; Egami, T.; Lee, H.N. Growth control of the oxidation state in vanadium oxide thin films. Appl. Phys. Lett. 2014, 105, 223515. [CrossRef]

36. Liu, X.; Wang, S.W.; Chen, F.; Yu, L.; Chen, X. Tuning phase transition temperature of $\mathrm{VO}_{2}$ thin films by annealing atmosphere. J. Phys. D Appl. Phys. 2015, 48, 265104. [CrossRef]

37. Rampelberg, G.; Schutter, B.D.; Devulder, W.; Martens, K.; Radu, I.; Detavernier, C. In situ X-ray diffraction study of the controlled oxidation and reduction in the $\mathrm{V}-\mathrm{O}$ system for the synthesis of $\mathrm{VO}_{2}$ and $\mathrm{V}_{2} \mathrm{O}_{3}$ thin films. J. Mater. Chem. C 2015, 3, 11357-11365. [CrossRef]

38. Sun, Y.; Xiao, X.; Xu, G.; Dong, G.; Chai, G.; Zhang, H.; Liu, P.; Zhu, H.; Zhan, Y. Anisotropic vanadium dioxide sculptured thin films with superior thermochromic properties. Sci. Rep. 2013, 3, 2756. [CrossRef] [PubMed]

39. Liu, G.H.; Deng, X.Y.; Wen, R. Electronic and optical properties of monoclinic and rutile vanadium dioxide. J. Mater. Sci. 2010, 45, 3270-3275. [CrossRef]

40. Xiao, L.; Su, Y.; Qiu, W.; Ran, J.; Liu, Y.; Wu, J.; Lu, F.; Shao, F.; Peng, P. First-principles investigation on solar radiation shielding performance of rutile $\mathrm{VO}_{2}$ filters for smart windows. Appl. Phys. Lett. 2016, 109, 193906. [CrossRef]

41. Takahashi, I.; Hibino, M.; Kudo, T. Thermochromic Properties of Double-Doped $\mathrm{VO}_{2}$ Thin Films Prepared by a Wet Coating Method Using Polyvanadate-Based Sols Containing W and Mo or W and Ti. Jpn. J. Appl. Phys. 2001, 40, 1391. [CrossRef]

42. Gao, Y.; Wang, S.; Luo, H.; Dai, L.; Cao, C.; Liu, Y.; Chen, Z.; Kanehira, M. Enhanced chemical stability of $\mathrm{VO}_{2}$ nanoparticles by the formation of $\mathrm{SiO}_{2} / \mathrm{VO}_{2}$ core/shell structures and the application to transparent and flexible $\mathrm{VO}_{2}$-based composite foils with excellent thermochromic properties for solar heat control. Energy Environ. Sci. 2012, 5, 6104-6110. [CrossRef]

43. Komine, T.; Nakagama, M. Fundamental Analysis for Visible-Light Communication System using LED Lights. IEEE Trans. Consum. Electron. 2004, 50, 100-107. [CrossRef]

44. Menounou, S.; Stassinakis, A.N.; Nistazakis, H.E.; Tzanakaki, A.; Sandalidis, H.G.; Tombras, G.S. Study and simulation on performance of a VLC communication system. In Proceedings of the 7th International Conference on Experiments/Process/System Modeling/Simulation \& Optimization, 7th IC-EPSMSO, Athens, Greece, 5-8 July 2017; Volume 2, pp. 457-464, ISBN 978-618-82173-3-1.

45. Ndjiongue, A.R.; Ferreira, H.C.; Ngatched, T.M. Visible Light Communications (VLC) Technology. Wiley Encycl. Electr. Electron. Eng. 2015, 1-15. [CrossRef]

46. De Lausnay, S.; De Strycker, L.; Goemaere, J.; Stevens, N.; Nauwelaers, B. Optical CDMA codes for an indoor localization system using VLC. In Proceedings of the 2014 3rd International Workshop in Optical Wireless Communications (IWOW), Funchal, Portugal, 17 September 2014; pp. 50-54. [CrossRef]

47. Ab-Rahman, M.S.; Shuhaimi, N.I.; Azizan, L.A.H.; Hassan, M.R. Analytical Study of Signal-to-Noise Ratio for Visible Light Communication by Using Single Source. J. Comput. Sci. 2012, 8, 141-144. [CrossRef]

48. Bekkali, A.; Naila, C.B.; Kazaura, K.; Wakamori, K.; Matsumoto, M. Transmission Analysis of OFDM-Based Wireless Services Over Turbulent Radio-on-FSO Links Modeled by Gamma-Gamma Distribution. IEEE Photonics J. 2010, 2, 510-520. [CrossRef]

49. Wang, T.Q.; Sekercioglu, Y.A.; Armstrong, J. Analysis of An Optical Wireless Receiver Using a Hemispherical Lens with Application in MIMO Visible Light Communications. J. Lightwave Technol. 2013, 31, 1744-1754. [CrossRef]

(C) 2019 by the authors. Licensee MDPI, Basel, Switzerland. This article is an open access article distributed under the terms and conditions of the Creative Commons Attribution (CC BY) license (http://creativecommons.org/licenses/by/4.0/). 